\title{
PERFIL DOS EGRESSOS DE UMA FACULDADE DE TECNOLOGIA E SEUS INTERESSES NA CRIAÇÃO DE UM PORTAL DO EGRESSO
}

\author{
Lilian Wrzesinski Simon*, Thais Hoffman Arnoni, Andressa Sasaki Vasques Pacheco \\ *E-mail: lilian.uffs@gmail.com \\ Universidade Federal de Santa Catarina, Universidade Federal da Fronteira Sul \\ DOI: $10.15628 /$ rbept.2020.9130
}

Artigo submetido em nov/2019 e aceito em mar/2020

\begin{abstract}
RESUMO
O objetivo desta pesquisa é analisar o perfil dos egressos de uma Faculdade de Tecnologia e seus interesses na criação de um Portal do Egresso, a ser estruturado como ferramenta de relacionamento por meio da oferta de benefícios e serviços. A pesquisa foi realizada com os egressos dos quatro cursos superiores de tecnologia da Faculdade Senac Florianópolis, diplomados a partir de 2014. Os resultados evidenciaram que os ex-alunos se mostraram satisfeitos com o curso e com a instituição e que pretendem dar continuidade aos estudos, já que a maioria está inserida no mercado de trabalho. Observa-se também que cerca de $70,00 \%$ deles demonstraram interesse em manter os dados atualizados em um Portal do Egresso a ser disponibilizado pela IES, a fim de usufruir de serviços e benefícios, estendendo o relacionamento para além das ações relativas ao encaminhamento profissional.
\end{abstract}

Palavras-chave: Gestão Universitária. Acompanhamento de Egressos. Portal do Egresso. Avaliação Institucional.

\section{PROFILE OF THE GRADUATES OF A TECHNOLOGY COLLEGE AND ITS INTERESTS IN THE CREATION OF AN ALUMNI PORTAL}

\begin{abstract}
The objective of this research is to analyze the profile of the graduates of a Faculty of Technology and their interests in the creation of an Egress Portal, to be structured as a relationship tool, by offering benefits and services. The research was conducted with the graduates of the four higher technology courses of the Senac Florianópolis College graduated from 2014. The results showed that the alumni were satisfied with the course and the institution, which intend to continue their studies and that most are in the labor market. It is also observed that about $70.00 \%$ showed interest in keeping the data updated in an Egress Portal to be made available by IES, in order to enjoy services and benefits, extending the relationship beyond the actions related to professional referral.
\end{abstract}

Keywords: University Management. Follow-up of Graduates. Alumni Portal. Institutional Evaluation. 


\section{INTRODUÇÃO}

As Instituições de Ensino Superior (IES) são organizações complexas e repletas de desafios em sua gestão, desafios que se estendem desde a captação de estudantes, a sustentação financeira, a qualidade do ensino e a inserção profissional dos egressos. A avaliação dos resultados da gestão universitária deve contar com a participação dos diversos grupos sociais que integram a comunidade acadêmica e a sociedade ao seu entorno, como os alunos, os professores, as empresas e os egressos.

Apesar de sua relevância para a gestão das IES, o acompanhamento de egressos é uma área ainda pouco desenvolvida na administração universitária brasileira. As instituições privadas são as que mais investem no relacionamento com esse público com o propósito de inseri-lo em suas estratégias de marketing para a captação de novos alunos (QUEIROZ, 2014).

Os egressos são uma importante fonte de informação sobre as constantes modificações do mercado de trabalho, permitindo o alinhamento de seus cursos à realidade enfrentada pelos diplomados no campo profissional (MACHADO, 2001). Portanto, incluir a participação dos egressos na avaliação institucional é indispensável para a gestão universitária.

Assim sendo, o relacionamento com os egressos se reveste de uma importância cada vez maior como instrumento de gestão nas IES, o que exige um posicionamento diferenciado de seus dirigentes, mediante a adoção de sistemas de acompanhamento que sejam atrativos para os diplomados e que instiguem a sua adesão ao cadastramento e ao relacionamento contínuo.

O objetivo deste artigo é analisar o perfil dos egressos de uma Faculdade de Tecnologia e seus interesses na criação de um Portal do Egresso, a ser estruturado como ferramenta de relacionamento por meio da oferta de benefícios e serviços.

A pesquisa foi desenvolvida na Faculdade Senac Florianópolis/SC. As Faculdades Senac integram as unidades educacionais do Serviço Nacional de Aprendizagem Comercial (SENAC), sendo instituições particulares sem fins lucrativos que se dedicam à oferta de cursos profissionais para o comércio de bens, serviços e turismo.

A regional de Santa Catarina compreende 27 unidades, destas, 10 Faculdades e outras seis unidades vinculadas ${ }^{1}$. A unidade de Florianópolis foi credenciada como Faculdade em 2002 e vem buscando reconhecimento no ramo da educação superior tecnológica. Atualmente, essa instituição oferece quatro cursos superiores de tecnologia.

Nas Faculdades Senac, a gestão dos egressos está vinculada ao Banco de Oportunidades, que tem por principal objetivo a divulgação de vagas de

1 Unidades vinculadas são estruturas específicas das IES mantidas pelos Serviços Nacionais de Aprendizagem, previstos na Portaria n. 1.005, de 27 de novembro de 2014, para oferta de cursos fora da Sede. 
emprego e de estágios, bem como o encaminhamento de alunos e egressos às suas vagas de interesse. O Banco de Oportunidades é uma estratégia institucional do Senac de Santa Catarina, cuja gestão é realizada pelo Departamento Regional e está em atividade desde abril de 2014.

Ainda não existe um Portal do Egresso setorizado que possa ser usado como instrumento de coleta de dados dos diplomados, nem uma iniciativa estruturada para tal, no âmbito da regional, que forneça subsídios informacionais acerca dos egressos para a gestão da IES. Entretanto, a sua adoção se faz oportuna e relevante para fomentar as decisões de planejamento estratégico, o marketing de relacionamento e a avaliação dos cursos pelo Sistema Nacional de Avaliação da Educação Superior (SINAES).

Os conceitos explorados como base para a construção deste estudo foram: a legislação da educação superior e a Lei n. 10.861, de 14 de abril de 2004, também conhecida como Lei do SINAES, a organização dos cursos superiores de tecnologia e a gestão de egressos.

\section{A LEGISLAÇÃO DA EDUCAÇÃO SUPERIOR E A LEI DO SINAES}

Embora a autonomia política e administrativa seja uma prerrogativa do sistema universitário brasileiro, conferida pela Constituição Federal de 1988 $(\mathrm{CF} / 88)$, as IES estão sujeitas às regulações educacionais, assim como manifestado desde o seu surgimento. O primeiro documento a normatizar a Educação Superior no país foi o Estatuto das Universidades Brasileiras (BRASIL, 1931), proposto, após a Revolução de 1930, pelo então ministro Dr. Francisco Campos. O Estatuto das Universidades Brasileiras foi regulamentado por meio do Decreto n. 19.851, de 11 de abril de 1931, que instituiu o regime universitário no Brasil.

Algumas décadas após a publicação desse documento, outro marco legal de destaque surgiu com a intenção de normatizar a educação superior, evidenciando como seu desenvolvimento se deu a passos lentos (FÁVERO, 2006). A Lei n. 5.540, de 28 de novembro de 1968, teve importância significativa para o sistema universitário, pois modificou as normas de sua organização e funcionamento, instituindo um modelo organizacional único para instituições públicas e privadas, bem como sua articulação com a escola média.

Os anos de 1980 marcaram o surgimento da avaliação, que foi posta a partir da década de 1990, por meio do Programa de Avaliação Institucional das Universidades Brasileiras (PAIUB), acompanhando as sucessivas transformações do sistema de educação superior (GOMES, 2003).

Nesse período, destaca-se também a Lei n. 9.394, de 20 de dezembro de 1996 - Lei de Diretrizes e Base da Educação (LDB), que traz um capítulo dedicado exclusivamente à educação superior, tratando, desde a finalidade desse nível de ensino e de sua abrangência (em cursos e programas) até informações sobre autorização e reconhecimento, dias letivos, frequência, certificações e validações, entre outros. 
Ao se referir à organização da educação nacional, a LDB (BRASIL,1996) apresenta em seu artigo 9 o um inciso que atribui à União a necessidade de assegurar um processo nacional de avaliação das IES com a cooperação dos sistemas educacionais. Para atender a essa prerrogativa, o PAIUB foi substituído pelo Exame Nacional de Cursos (ENC), cuja principal finalidade era avaliar se os cursos de graduação ofertados pelas IES estavam alinhados com as expectativas do sistema econômico (DIAS SOBRINHO, 2010).

Esse processo se estendeu até 2003, quando iniciaram, no âmbito do Instituto Nacional de Estudos e Pesquisas Educacionais Anísio Teixeira (INEP), as discussões acerca da criação de novas métricas de avaliação, instituídas pela Lei do SINAES. A Lei n. 10.861, de 14 de abril de 2004, tem por objetivo assegurar o processo de avaliação das IES e dos cursos de graduação e 0 desempenho dos estudantes.

$\mathrm{Na}$ definição dos processos avaliativos dos cursos superiores, a referida Lei aponta a obrigatoriedade de se considerar 10 dimensões institucionais. A nona dimensão, que trata das políticas de atendimento aos estudantes, inseriu os egressos entre os atores que devem participar do processo avaliativo, enfatizando aspectos como o acompanhamento dos estudantes quanto à inserção no mercado de trabalho e a educação continuada/continuidade dos estudos.

No desdobramento dos parâmetros especificados nos Instrumentos de Avaliação Institucional Externa, que subsidiam os atos de credenciamento e transformação da organização acadêmica presencial, essa dimensão está inserida no eixo 3 - Políticas Acadêmicas - que, além do atendimento aos estudantes, reforça a necessidade da existência de políticas e de ações de acompanhamento dos egressos, bem como a atuação dos egressos da IES no âmbito socioeconômico - entendendo por egresso aquele aluno que cursou e concluiu um curso superior (INEP, 2014).

\subsection{OS CURSOS SUPERIORES DE TECNOLOGIA}

Os cursos superiores de tecnologia estão enquadrados na LDB como educação profissional tecnológica em nível de graduação. O Conselho Nacional de Educação (CNE) publicou em 2001, por meio do Parecer CNE/CES n. 436, de 2 de abril de 2001, uma série de orientações sobre a formação dos tecnólogos. Na sequência, em 2002, foram publicadas as Diretrizes Curriculares Nacionais (DCNs) para a organização e 0 funcionamento dos Cursos Superiores de Tecnologia, por meio da Resolução CNE/CP n. 3, de 18 de dezembro de 2002.

Em 2006, foi lançado pelo Ministério da Educação (MEC) o primeiro Catálogo Nacional dos Cursos Superiores de Tecnologia como um guia sobre os perfis profissionais. O catálogo, além de institucionalizar as denominações, organizou os cursos por eixo tecnológico e apresentou as cargas horárias, infraestrutura recomendada para cada curso e perfil profissional esperado. Em 2010 e 2016, foram publicados novos catálogos para os cursos superiores de 
tecnologia, com normas revistas e atualizadas a serem seguidas pelas IES que desejam ofertar essa modalidade de ensino (MEC, 2017).

Segundo dados do Censo de 2015 do INEP (2015b), o número de ingressantes em cursos superiores de tecnologia foi de 516.965 alunos, representando $18 \%$ do número total de ingressantes. Do total de matrículas da educação superior, os tecnólogos representavam 12,7\%, com um total de 1.010.142 alunos matriculados.

\title{
2.2 GESTÃO DE EGRESSOS
}

A participação dos egressos nos processos avaliativos das IES está entre os principais motivadores para o acompanhamento deste público. A inserção profissional pode ser uma poderosa ferramenta de marketing, mas o objetivo de conhecer a opinião dos egressos está relacionado com vários aspectos da gestão universitária, que permitem uma avaliação mais realística da qualidade do ensino. De acordo com Meira e Kurcgant (2009, p. 482):

\begin{abstract}
O egresso enfrenta em seu cotidiano de trabalho situações complexas, que o levam a confrontar as competências desenvolvidas, durante o curso, com as requeridas no exercício profissional. Pode, a partir daí, avaliar a adequação da estrutura pedagógica do curso que foi vivenciado, bem como os aspectos intervenientes no processo de formação acadêmica.
\end{abstract}

O estabelecimento de vínculos com os egressos possibilita um melhor posicionamento social e profissional dos formados e dos novos alunos, uma vez que uma rede de relacionamento se forma, apresentando também a possibilidade de retorno do graduado para a realização de outro curso ofertado na IES (MICHELAN et al., 2009).

As formas de relacionamento apresentadas por Michelan et al. (2009) estão interligadas entre si: o vínculo institucional com os egressos é a chave para a captação de informações úteis para a avaliação, a melhoria da inserção profissional, o retorno dos graduados e para fomentar o marketing de relacionamento.

Segundo Madruga (2006), o marketing de relacionamento é uma importante ferramenta no processo de interação com o cliente, cujo objetivo é agregar valores que atendam às suas necessidades e mantenham uma relação duradoura com a empresa visando a estabelecer, a desenvolver e a manter trocas relacionais de sucesso.

O conceito de marketing de relacionamento de Madruga (2006) corrobora com a concepção de Dias (2003, p. 6) que estabelece o marketing de relacionamento como "[...] um método para deixar o cliente fidelizado visando [a] construir uma relação duradoura".

A visão do estudante e, consequentemente, do egresso do ensino superior como cliente é permeada de contradições na literatura educacional. 
Portanto, cabe ressaltar que esses conceitos estão sendo apresentados na ótica da gestão, do estabelecimento de redes de relacionamento com os diplomados, o que é fundamental para que o egresso possa ser envolvido e desperte o interesse de participar da vida institucional após a formatura.

Conforme apontam Queiroz e De Paula (2016, p. 12), o egresso deve sentir-se como um "sempre aluno", o que permite que ele estabeleça uma relação contínua com a IES, desenvolvendo, assim, o sentimento de pertencimento. Os autores afirmam que inserir o egresso na pauta de atividades da IES Ihe reveste de importância, favorecendo um comportamento mais ativo e colaborativo para com a instituição onde realizou seus estudos e obteve seu diploma (QUEIROZ; PAULA, 2016).

A fim de sintetizar os elementos que justificam a criação de um sistema para a gestão de egressos, Queiroz (2014) apresenta um quadro com as principais necessidades da IES e da sociedade, ou seja, as necessidades dos egressos que precisam ser observadas no momento da construção de um programa de ex-alunos.

Quadro 1 - Necessidades dos egressos e da IES associadas a um programa de ex-alunos

\begin{tabular}{|c|c|}
\hline \multirow{2}{*}{$\begin{array}{c}\text { NECESSIDADE DA } \\
\text { SOCIEDADE/EGRESSOS }\end{array}$} & NECESSIDADE DA INSTITUIÇÃO \\
\hline & \\
\hline Oportunidade de emprego & Consolidação da imagem e da marca \\
\hline & Recursos financeiros \\
\hline Atividade culturais & . \\
\hline & \\
\hline Atividades extensionistas & Verbas orçamentárias governamentais \\
\hline Educação continuada & Missão institucional \\
\hline Obtenção de novos títulos & Ampliação de atuação \\
\hline Parcerias institucionais & Relevância social \\
\hline Incubação de empresas & Parcerias institucionais \\
\hline Programas sociais & Adequação de currículos com as \\
\hline Satisfação de retorno pessoal e gratidão & Avaliação de resultados \\
\hline
\end{tabular}

Fonte: Queiroz (2014, p. 26)

Cabe destacar que essas necessidades variam de acordo com o perfil de cada instituição, uma vez que o sistema universitário brasileiro não é homogêneo. O perfil e os interesses dos estudantes e egressos das IES privadas diferem em vários aspectos do público que frequenta as universidades públicas. Essas especificidades exigem um alinhamento das ações a serem 
adotadas para a gestão do relacionamento com os egressos e com a cultura organizacional da IES, considerando os objetivos e as perspectivas dos seus graduados.

O quadro apresentado por Queiroz (2014) foi elaborado como uma proposta para uma instituição pública federal, tomando como base o modelo norte-americano de universidade. Esse modelo, assim como o brasileiro, tem como uma de suas principais características a heterogeneidade, de modo que pondera questões importantes, tanto para instituições públicas como privadas. Além das necessidades apontadas no Quadro 1, aspectos, como a captação de novos alunos, são um fator que as IES brasileiras não podem deixar em segundo plano. No caso das instituições particulares, a ampliação do campo de atuação no mercado também é indispensável para o crescimento e a sustentação financeira da IES.

Essas instituições também valorizam a progressão de seus diplomados na carreira como uma poderosa ferramenta de marketing institucional (KALSBEK, 2003), uma vez que os seus cursos são mais voltados para o campo profissional. Desse modo, seus investimentos em educação continuada estão direcionados para as expectativas do mercado de trabalho, como a oferta de cursos de especialização e qualificação, por exemplo.

Na perspectiva dos egressos, a criação de um canal de relacionamento possibilita a oferta de benefícios, como: acesso à biblioteca, periódicos científicos e ao perfil dos outros egressos, desconto em cursos, parcerias de desconto em produtos e serviços, eventos exclusivos para os egressos, eventos sobre gestão, programas de viagens e serviços de carreira, entre outros (TEIXEIRA; MACCARI, 2014). A oferta desses serviços é uma forma de gerar nos egressos o interesse em se cadastrar no sistema e manter 0 relacionamento com a sua instituição, sendo visto como uma importante estratégia a ser explorada pela gestão universitária.

\section{METODOLOGIA}

A construção de um sistema de acompanhamento de egressos requer 0 conhecimento das principais características do seu público-alvo, o que também é indispensável para a gestão estratégica da IES direcionar os rumos de suas decisões ao encontro das expectativas da sociedade que busca ali a sua formação acadêmica e profissional.

Sendo assim, a natureza desta pesquisa é aplicada, pois seu objetivo é traçar o perfil dos egressos dos quatro cursos ofertados na Faculdade Senac Florianópolis e seus interesses na criação de um Portal do Egresso. Para tanto, utilizou-se de uma abordagem quanti-qualitativa, com 0 uso de fontes bibliográficas, documentais e dados empíricos, resultando em um estudo de caso de caráter descritivo.

A coleta dos dados contou com o suporte de fontes secundárias, como as legislações, os documentos institucionais e as publicações sobre o assunto, e de fontes primárias, como as informações coletadas por meio de um 
questionário aplicado aos ex-alunos que obtiveram seus diplomas no período entre 2014 e 2017.

A Faculdade Senac Florianópolis já formou, desde 2002, ano do seu credenciamento, cerca de 1.728 alunos, mas, como o sistema acadêmico utilizado até o ano de 2013 foi descontinuado e substituído pelo sistema atualmente em uso, optou-se por contatar apenas os formados após o ano de 2014. Esse recorte temporal se deu em função da acessibilidade aos dados de contato dos ex-alunos que estão registrados no sistema.

Esse sistema acadêmico não gera relatório de alunos formados. Por esse motivo, a forma de verificação do público apto a participar da pesquisa se deu pela consulta às atas de colação de grau, arquivadas na secretaria acadêmica da Faculdade. Essa consulta possibilitou o estabelecimento do universo da pesquisa, composto de 353 egressos.

De posse do quantitativo de egressos a serem contatados e das informações necessárias para acessá-los, previamente levantadas junto à secretaria acadêmica, foi encaminhado um questionário com perguntas fechadas, estruturado na plataforma de formulários do Google para o e-mail dos diplomados. Algumas coordenações de curso mantêm, de forma independente, grupos nas redes sociais, então, nesse caso, foi compartilhado o link do questionário em grupos do Facebook ou enviado por mensagem privada no Linkedin.

Em função de haver possibilidade de adesão de alunos formados antes de 2014 nesses espaços, foi acrescentada, como forma de controle, a opção "antes de 2014" na pergunta sobre o ano de formatura. As respostas dos egressos que assinalaram a opção "antes de 2014" nessa questão foram descartadas. Dos 69 questionários respondidos, foram considerados válidos, portanto, 46, os quais correspondem à amostra da pesquisa.

O questionário composto de 15 perguntas foi organizado em duas partes, a primeira com 12 questões sobre o perfil do egresso e a segunda com três questões para identificar o grau de importância que os participantes atribuem à oferta de benefícios e serviços em um Portal do Egresso, caso venha a ser construído na Faculdade Senac Florianópolis.

A seguir serão apresentados e analisados os dados obtidos na pesquisa.

\section{RESULTADOS E DISCUSSÕES}

O SENAC/SC atua no estado desde 1947 e tem como missão "educar para o trabalho em atividades do comércio de bens, serviços e turismo". Desde seu credenciamento em 2002, a Faculdade Senac Florianópolis vem formando profissionais para atuar nas áreas de gestão e tecnologia (SENAC, 2017).

Conforme já mencionado, a gestão dos seus egressos está vinculada ao "Banco de Oportunidades", cujo objetivo principal é a divulgação de vagas de emprego e de estágios, bem como o encaminhamento de alunos e egressos às vagas que Ihes interessam. Esse programa foi implantado em abril de 2014 
como uma estratégia institucional do SENAC/SC e sua gestão é realizada pelo Departamento Regional que compreende todas as faculdades e unidades do SENAC espalhadas pelo Estado de Santa Catarina (SENAC, 2017).

\subsection{PERFIL DOS EGRESSOS DA FACULDADE SENAC FLORIANÓPOLIS}

Para traçar o perfil dos egressos, inicialmente buscou-se levantar no sistema acadêmico o quantitativo de diplomas conferidos no período, distribuídos de acordo com os cursos realizados pelos egressos.

A Faculdade Senac Florianópolis oferta vestibular semestralmente, portanto, as formaturas também são semestrais, com exceção do curso de Gestão Comercial, que, a partir de 2013, não teve mais entradas no mês de julho. Outro aspecto importante a considerar é que o Curso de Análise e Desenvolvimento de Sistemas iniciou suas atividades em 2014 e, por isso, só possui egressos a partir de 2016/2, considerando o tempo de duração do curso de cinco semestres. formatura.

A Tabela 1 apresenta o quantitativo de alunos por curso e semestre de

Tabela 1 - Levantamento do quantitativo de egressos

\begin{tabular}{|c|c|c|c|c|}
\hline \multirow[b]{2}{*}{ CURSO } & \multicolumn{4}{|c|}{ LEVANTAMENTO DOS EGRESSOS } \\
\hline & $\begin{array}{l}\text { Gestão da } \\
\text { Tecnologia da } \\
\text { Informação }\end{array}$ & $\begin{array}{l}\text { Processos } \\
\text { Gerenciais }\end{array}$ & $\begin{array}{l}\text { Gestão } \\
\text { Comercial }\end{array}$ & $\begin{array}{c}\text { Análise e } \\
\text { Desenvolvimento } \\
\text { de Sistemas }\end{array}$ \\
\hline $2014 / 1$ & 17 & 31 & 13 & \\
\hline $2014 / 2$ & 31 & 29 & 12 & \\
\hline $2015 / 1$ & 12 & 27 & 10 & \\
\hline $2015 / 2$ & 25 & 14 & 2 & \\
\hline $2016 / 1$ & 23 & 26 & 14 & \\
\hline $2016 / 2$ & 15 & 12 & 1 & 5 \\
\hline $2017 / 1$ & 7 & 10 & 10 & 7 \\
\hline TOTAL CURSO & 130 & 149 & 62 & 12 \\
\hline TOTAL GERAL & \multicolumn{4}{|c|}{353} \\
\hline
\end{tabular}

Fonte: Dados da pesquisa 
De um universo de 353 diplomas conferidos, observou-se que o curso de Processos Gerenciais se destacou sobre os demais, com cerca de $42,20 \%$ dos diplomas, seguido pelo curso de Gestão da Tecnologia da Informação, com aproximadamente $37,00 \%$ dos títulos. O curso de Gestão Comercial, cuja entrada é anual, conferiu grau a $17,50 \%$ dos graduados e o curso de Análise e Desenvolvimento de Sistemas, a 3,30\% dos egressos, o que se justifica pela sua implantação recente.

A adesão à pesquisa foi voluntária, culminando em uma amostra casual simples, composta de 46 respostas válidas. A Figura 1 apresenta a distribuição dos participantes de acordo com o curso em que se formaram.

Figura 1: Curso em que se formou

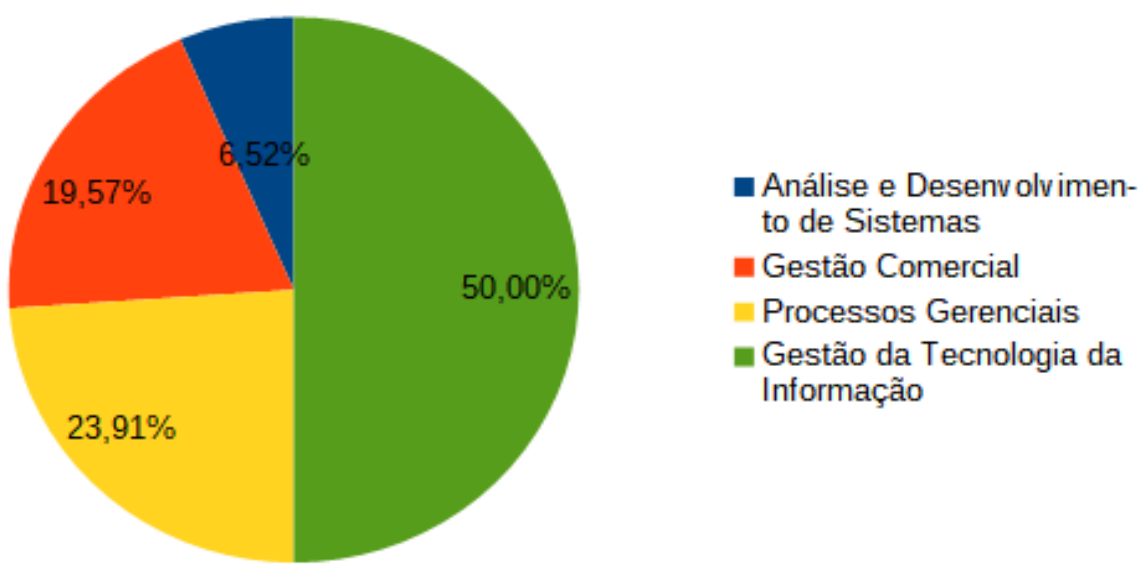

Fonte: Dados da pesquisa

Do total de respondentes, 23 , ou $50,00 \%$, são egressos do curso de Gestão da Tecnologia da Informação, o que evidencia que houve uma participação acentuada dos egressos desse curso, quando se compara o total de participantes com o total de diplomas conferidos entre 2014 e 2017. A proporção de participantes entre os formados neste curso durante o período corresponde a $17,70 \%$ do total. O segundo curso com maior número de respondentes foi o de Processos Gerenciais, com 11 pessoas ou 23,91\% das participações. Esse é o curso que possui o maior número de egressos do total geral no período, o que reflete em uma menor participação proporcional, com índice em torno de $7,40 \%$ dos diplomados. O curso de gestão comercial contou com nove respondentes ou $19,57 \%$ das participações, o que perfaz a proporção de $14,50 \%$ dos egressos do período. Embora no curso de Análise e Desenvolvimento de Sistemas tenha-se obtido o menor número de participações (três ou 6,52\%), foi o curso com a maior participação proporcional, perfazendo o índice de $25,00 \%$ dos diplomados, uma razão de 1 para 4 egressos. 
Figura 2: Distribuição dos participantes por ano de formatura

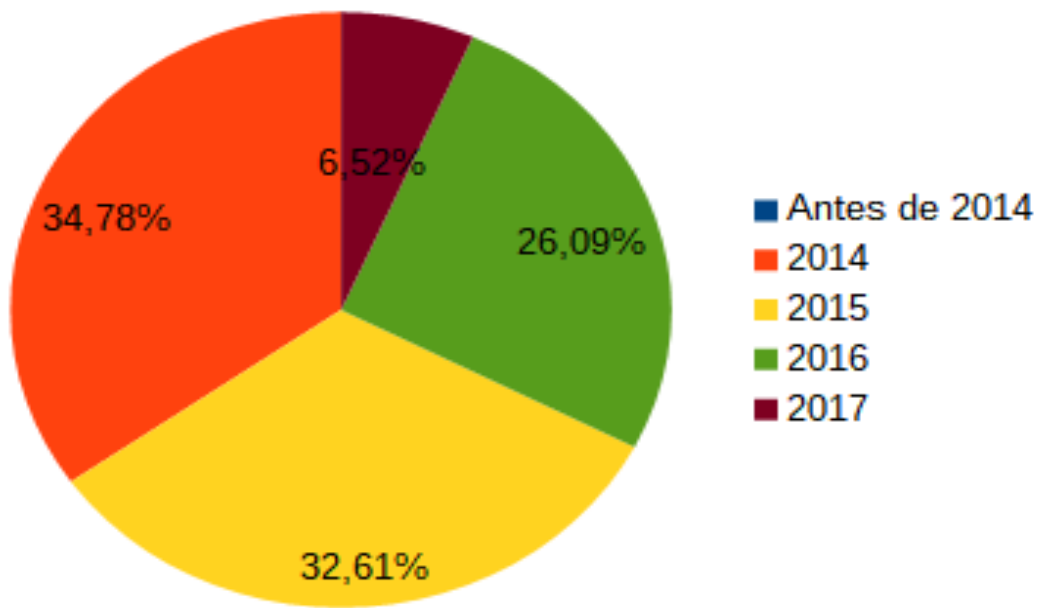

Fonte: Dados da pesquisa

Com relação ao ano de formatura, o ano de 2014 obteve o maior número de respondentes, perfazendo quase $35,00 \%$ de participantes. Esse índice equivale a aproximadamente $12,00 \%$ dos egressos diplomados nos dois semestres do respectivo ano. Os formados nos dois semestres do ano de 2015 correspondem ao percentual de $32,61 \%$ dos respondentes, o que perfaz em torno de $16,50 \%$ dos egressos titulados nesse ano. Em 2016, cerca de 26,09\% dos respondentes obtiveram seu diploma, o que soma $12,50 \%$ dos egressos do ano. $\mathrm{O}$ ano de 2017 contou com um menor índice de respondentes, cerca de $6,52 \%$ do total da pesquisa. Esse número contempla aproximadamente 9,00\% dos egressos que colaram grau no ano.

Figura 3: Tempo de duração do curso

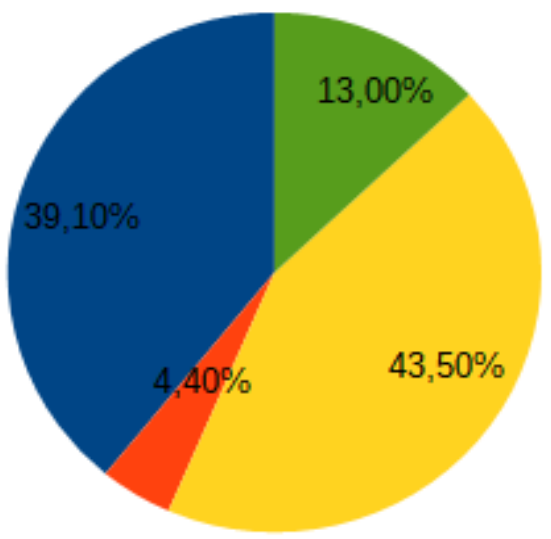

4 semestres (prazo regular do curso)

- 4 semestres (precisei de mais tempo para concluir)

5 semestres (prazo regular do curso)

5 semestres (precisei de mais tempo para concluir)

Fonte: Dados da pesquisa

Em relação ao tempo de duração do curso e ao período necessário para a sua conclusão, observa-se que cerca de $83,00 \%$ dos respondentes concluíram o curso no tempo previsto, sem necessidade de aditamento do prazo para a diplomação, enquanto $17,00 \%$ deles precisaram de mais tempo 
para receber a sua titulação. A maioria dos egressos dos cursos de graduação da Faculdade Senac Florianópolis permaneceu por cerca de dois anos ou dois anos e meio frequentando a instituição.

A Figura 4 ilustra a distribuição da idade dos egressos que participaram da pesquisa.

Figura 4: Idade dos egressos

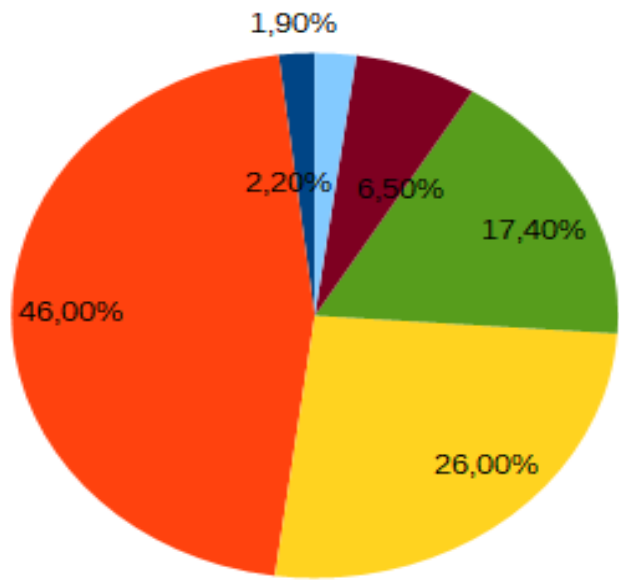

- Até 20 anos

- Entre 21 e 30 anos

Entre 31 e 40 anos

- Entre 41 e 50 anos

- Entre 51 e 60 anos

Mais de 60 anos

Fonte: Dados da pesquisa

No que se refere à idade, $46,00 \%$ dos respondentes estão na faixa entre os 21 e 30 anos; seguido de $26,00 \%$ pertencentes à faixa de 31 a 40 anos; $17,40 \%$ estão na faixa entre 41 e 50 anos; $6,50 \%$ possuem entre 51 e 60 anos; e 2,20\% têm idade superior a 60 anos. Apenas $1,90 \%$ dos egressos tinham 20 anos ou menos no momento da formatura, indicando que eles ingressaram no ensino superior tecnológico assim que concluíram o ensino médio. Ao considerar que nem todos os participantes podem ter concluído o ensino médio na idade regular, esse percentual tende a ser mais elevado.

Sobre os motivos que os levaram a escolher a Faculdade Senac Florianópolis, a questão elaborada era de múltipla escolha, permitindo ao participante assinalar, entre as alternativas propostas, aquelas que 0 influenciaram nesse processo: 
Figura 5: Motivos que levaram os participantes a escolher a Faculdade Senac Florianópolis

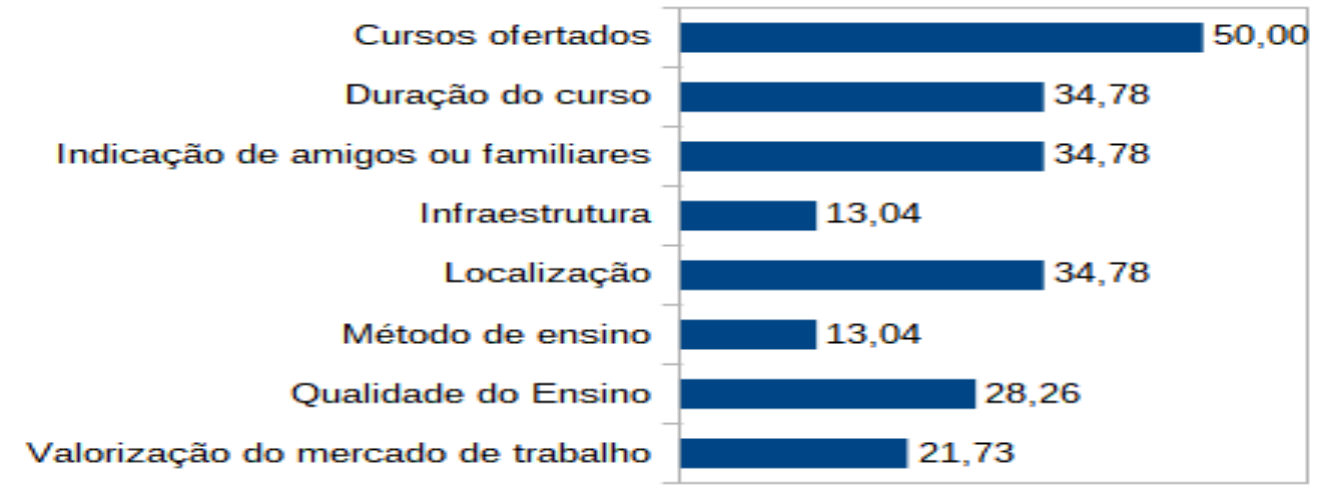

Fonte: Dados da pesquisa

Com relação aos motivos de escolha do curso e da instituição de ensino, o item cursos ofertados despontou entre os motivos de escolha, indicado por $50,00 \%$ dos egressos. Isso evidencia que a maioria dos estudantes optou pela Faculdade Senac Florianópolis em busca de um curso alinhado com as suas expectativas ou necessidades. O tempo de duração do curso, a localização da IES e a indicação de amigos ou família também foram aspectos determinantes na escolha dos cerca de $35,00 \%$ dos egressos que apontaram os três indicadores. Na sequência são apontadas a qualidade do ensino por $28,26 \%$ dos respondentes e a valorização no mercado de trabalho por $21,73 \%$ dos diplomados. O método de ensino e a infraestrutura mostram-se menos impactantes na decisão de escolha pela Faculdade Senac Florianópolis para se graduar, ambos sendo apontados por $13,04 \%$ dos respondentes.

Acerca da avaliação do curso, observa-se na Figura 6 que houve uma avaliação predominantemente positiva.

Figura 6: Avaliação do curso

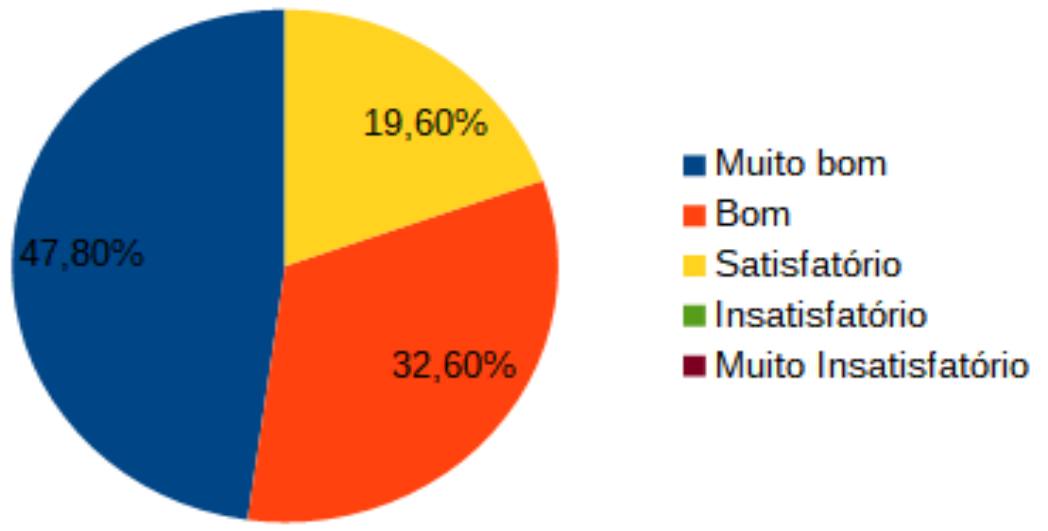

Fonte: Dados da pesquisa

A avaliação do curso feito no Senac compreendeu índices de 47,80\% dos egressos considerando como muito bom o curso no qual se formaram; e $32,60 \%$ consideraram o curso como bom. Isso demonstra que praticamente 
$80 \%$ dos respondentes acreditam que o seu curso está acima da média de suas expectativas, ao passo que o índice restante de $19,60 \%$ apontou o curso realizado como satisfatório. Nesse quesito, não houve nenhum respondente que declarou que o curso foi insatisfatório ou muito insatisfatório.

Essa satisfação também pode estar refletida no desejo de dar continuidade aos estudos, apresentada em dados na Figura 7.

Figura 7: Desejo de continuar os estudos

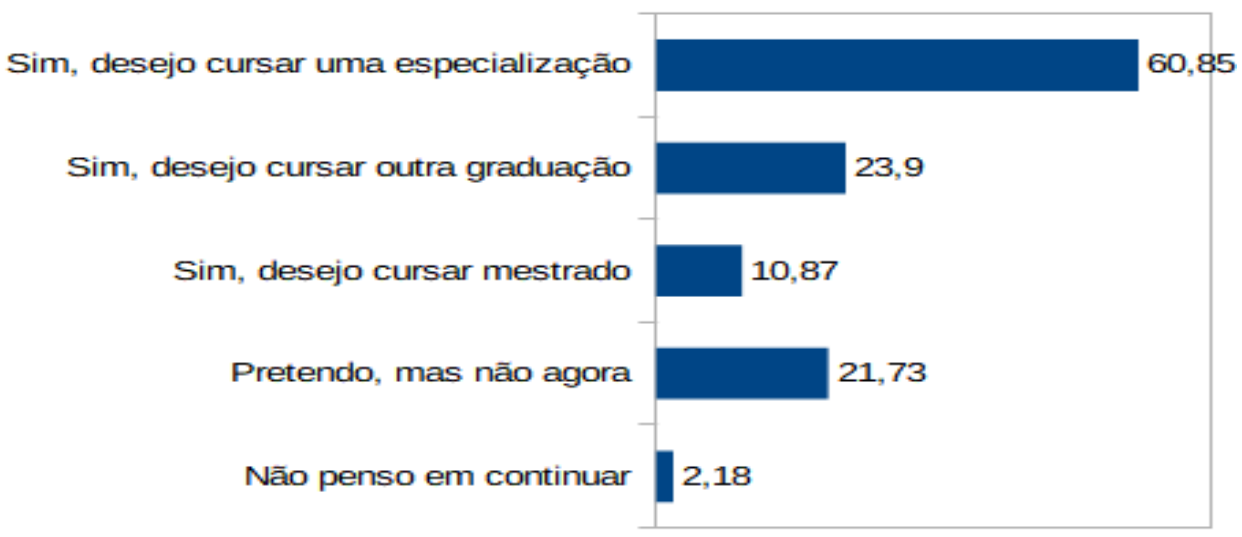

Fonte: Dados da pesquisa

Quando questionados sobre o desejo de dar continuidade aos estudos, $60,85 \%$ dos respondentes apontaram que pretendem elevar seu nível de formação cursando uma especialização, cerca de $24 \%$ declararam que gostariam de cursar outra graduação, outros $21,73 \%$ apontaram que desejam prosseguir nos estudos, mas não agora, 10,87\% demonstraram o desejo de cursar mestrado e apenas um deles $(2,18 \%)$ manifestou não ter desejo de voltar a estudar.

Com relação à atividade profissional, a maioria dos participantes já estava inserida no mercado de trabalho no período da pesquisa, conforme demonstra a Figura 8.

Figura 8: Atividade profissional dos egressos

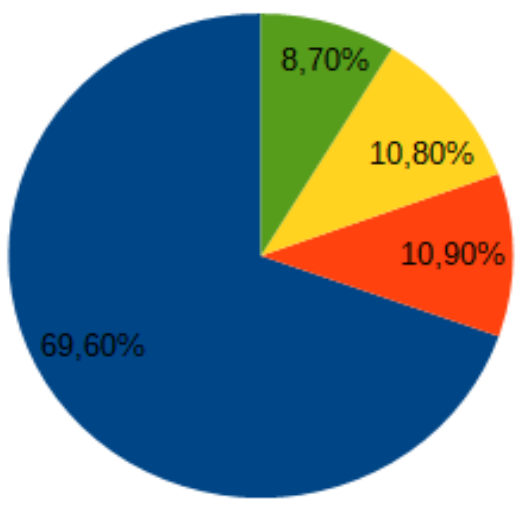

Sim, trabalho na área da minha formação

- Sim, mas trabalho em área diversa da minha formação

nim, trabalho em área ligada indiretamente com a minha formação

n Não estou trabalhando

Fonte: Dados da pesquisa 
Quando questionados sobre o mercado de trabalho e sobre a relação da área de formação com a área de atuação profissional, $69,60 \%$ dos diplomados disseram que trabalham na área de formação acadêmica, seguidos de $10,80 \%$ que atuam em área indiretamente ligada com a sua formação. O percentual de respondentes que trabalha em área diversa da sua formação é de $10,90 \%$, ao passo que apenas $8,70 \%$ não estão ativos no mercado de trabalho. Cabe destacar que cerca de 91,30\% também apontaram que já trabalhavam antes de iniciarem os estudos e permaneceram exercendo atividade remunerada durante o período em que estavam estudando.

Figura 9: Faixa de renda dos participantes

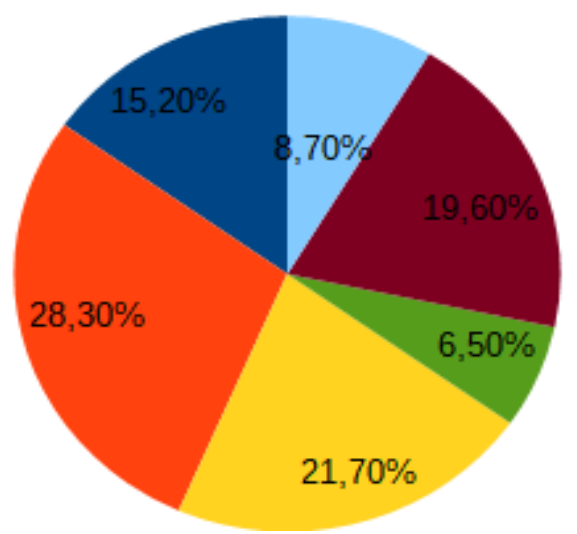

- Entre $\mathrm{R} \$ 1001,00$ e $\mathrm{R} \$ 2000,00$

n Entre $\mathrm{R} \$ 2001,00$ e $\mathrm{R} \$ 3000,00$

Entre $\mathrm{R} \$ 3001,00$ e $\mathrm{R} \$ 4000,00$

antre $\mathrm{R} \$ 4001,00$ e $\mathrm{R} \$ 5000,00$

Mais de $\mathrm{R} \$ 5000,00$

Não estou exercendo atividade remunerada

Fonte: Dados da pesquisa

Sobre a renda auferida pelos egressos, dos $91,3 \%$ que estão exercendo atividade remunerada, observou-se que $47,8 \%$ possuem renda superior a $R \$$ $3.001,00$, seguidos de $28,3 \%$ cuja faixa de renda encontra-se entre $R \$$ $2.001,00$ a $R \$ 3.000,00$ e que $15,2 \%$ possuem renda entre $R \$ 1.001,00$ e $R \$$ 2.000,00. Não houve participantes da pesquisa que relataram estarem exercendo atividade remunerada e recebendo menos de $R \$ 1.000,00$ por mês.

A evolução da remuneração à medida que os estudos avançaram também foi um aspecto destacado na pesquisa. Responderam a essa questão apenas os egressos que trabalharam antes e durante o período de realização do curso e que estavam exercendo atividade remunerada durante a aplicação da pesquisa. 
Figura 10: Evolução da remuneração

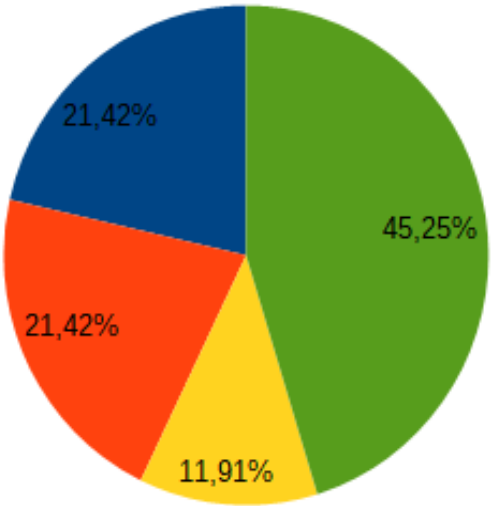

Fonte: Dados da pesquisa
- Sim, para os dois casos

- Aumentou apenas após a formatura

n Não aumentou, continua igual, sendo corrigida apenas de acordo com a legislação vigente ou dissídio da categoria

n Não aumentou, continua igual, sendo corrigida apenas de acordo com a legislação vigente ou dissídio da categoria

Nesse quesito, aproximadamente $55,00 \%$ dos profissionais pesquisados apontaram que os rendimentos foram aumentando em decorrência dos estudos e/ou após a formatura, ao passo que $45,25 \%$ não receberam aumentos reais consideráveis em seus salários à medida que os estudos avançaram e nem mesmo após a formatura, ou seja, permaneceram com a remuneração sendo corrigida apenas de acordo com a legislação vigente. Os egressos que receberam aumento salarial apenas após a conclusão dos estudos correspondem a $21,42 \%$ dos participantes da pesquisa.

\subsection{INTERESSES DOS GRADUADOS DA FACULDADE SENAC FLORIANÓPOLIS AO PARTICIPAR DE UM PORTAL DO EGRESSO}

A segunda parte da pesquisa pretendeu identificar o interesses de os egressos participarem de um Portal do Egresso, caso venha a ser implantado na Faculdade Senac Florianópolis. Nessa etapa, os egressos deveriam sinalizar o grau de importância de cada um dos 21 serviços/benefícios listados, conforme o nível de importância relegado a cada quesito como motivador para sua participação no sistema de acompanhamento de egressos.

A classificação das respostas ocorreu por meio da utilização da escala Likert, com as seguintes variáveis: É irrelevante; É pouco importante; Não é importante agora, mas poderá ser futuramente; É muito importante; É indispensável.

A Figura 11 apresenta os resultados encontrados: 
Figura 11 - Benefícios e serviços e sua relevância na opinião dos egressos

\section{BENEFÍCIOS OU SERVIÇOS}

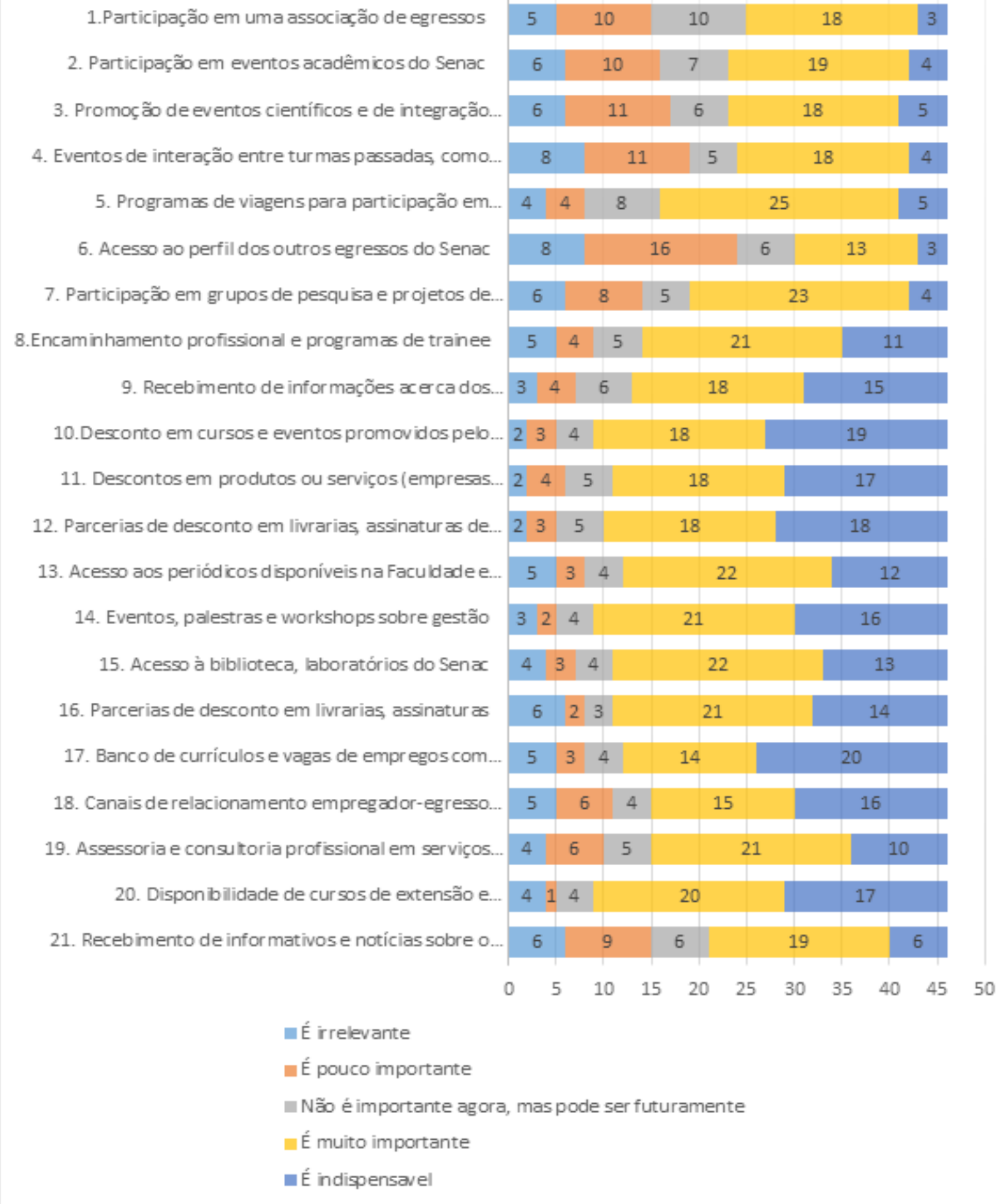

Fonte: Dados da pesquisa

Para fins de análise, foi calculado o percentual de respondentes que selecionaram as opções "é muito importante" e, "é indispensável". Com base nos valores obtidos em cada tópico, foi calculada a média dos resultados, representada por $65,00 \%$. Dos 21 itens avaliados, 62,00\% ficaram com 
percentual acima da média.

Foram calculados, também, os quartis inferior e superior, conforme apresentado na Tabela 2:

Tabela 2: Quartis inferior e superior

\begin{tabular}{|c|c|c|}
\hline Valor & Frequência & Frequência acumulada \\
\hline $34,7 \%$ & 1 & 1 \\
\hline $45.6 \%$ & 1 & 2 \\
\hline $47,8 \%$ & 1 & 3 \\
\hline $48,2 \%$ & 1 & 4 \\
\hline $50 \%$ & 2 & 6 \\
\hline $54,3 \%$ & 1 & 7 \\
\hline $58,6 \%$ & 1 & 8 \\
\hline $67,3 \%$ & 2 & 10 \\
\hline $69,5 \%$ & 1 & 11 \\
\hline $71,7 \%$ & 1 & 12 \\
\hline $73,9 \%$ & 2 & 13 \\
\hline $76 \%$ & 3 & 17 \\
\hline $78,2 \%$ & 2 & 19 \\
\hline $80,4 \%$ & 2 & 21 \\
\hline
\end{tabular}

Fonte: Dados da pesquisa

Com base nos dados da Tabela 2, verificou-se que o quartil inferior se encontra na 6⿳亠丷厂 posição, destacando-se os itens do Quadro 3 em vermelho. Os percentuais apresentados correspondem à quantidade de respondentes que indicaram as opções "é indispensável" e "é muito importante". 
Quadro 3 - Benefícios ou serviços - Quartil inferior

\begin{tabular}{|l|c|}
\multicolumn{1}{|c|}{ Benefício ou Serviço } & $\%$ \\
\hline 1.Participação em uma associação de egressos & $46 \%$ \\
\hline 2. Participação em eventos acadêmicos do Senac & $50 \%$ \\
\hline $\begin{array}{l}\text { 3. Promoção de eventos científicos e de integração, exclusivos aos } \\
\text { egressos }\end{array}$ & $50 \%$ \\
\hline $\begin{array}{l}\text { 4. Eventos de interação entre turmas passadas, como por exemplo: } \\
\text { encontros de turma, jantares ou almoços }\end{array}$ & $48 \%$ \\
\hline 6. Acesso ao perfil dos outros egressos do Senac & $35 \%$ \\
\hline 7. Participação em grupos de pesquisa e projetos de extensão & $48 \%$ \\
\hline
\end{tabular}

Fonte: Dados da pesquisa

Ainda com base nos dados da Tabela 2, verificou-se que o quartil superior se encontra na 17aㅡ posição, destacando-se os itens do Quadro 4 em azul. Os percentuais apresentados correspondem à quantidade de respondentes que indicaram as opções "é indispensável" e "é muito importante".

Quadro 4 - Benefícios ou serviços - Quartil superior

\begin{tabular}{|l|c|}
\hline \multicolumn{1}{|c|}{ Benefício ou Serviço } & $\%$ \\
\hline $\begin{array}{l}\text { 10.Desconto em cursos e eventos promovidos pelo Senac ou } \\
\text { instituições parceiras }\end{array}$ & $81 \%$ \\
\hline 11. Descontos em produtos ou serviços (empresas parceiras) & $76 \%$ \\
\hline $\begin{array}{l}\text { 12. Parcerias de desconto em livrarias, assinaturas de revistas e jornais } \\
\text { científicos }\end{array}$ & $78 \%$ \\
\hline 14. Eventos, palestras e workshops sobre gestão & $81 \%$ \\
\hline
\end{tabular}




\begin{tabular}{|l|c|}
\hline 15. Acesso à biblioteca, laboratórios do Senac & $76 \%$ \\
\hline 16. Parcerias de desconto em livrarias, assinaturas & $76 \%$ \\
\hline $\begin{array}{l}\text { 20. Disponibilidade de cursos de extensão e qualificação profissional, } \\
\text { gratuitos para os egressos }\end{array}$ & $78 \%$ \\
\hline
\end{tabular}

Fonte: Dados da pesquisa

Dos itens constantes no quartil inferior, observou-se que o menor índice, apontado com menor relevância pelos alunos, refere-se ao acesso ao perfil dos outros egressos da Faculdade Senac Florianópolis.

Dos itens relativos ao quartil superior, observou-se como de maior relevância: Desconto em cursos e eventos promovidos pelas Faculdades Senac ou instituições parceiras e Eventos, palestras e workshops sobre gestão.

Alguns dos itens apontados pelos alunos, como descontos em cursos e eventos da Faculdade Senac Florianópolis ou parceiras e eventos e demais atividades sobre gestão, já estão disponíveis ao acesso dos egressos, mas verificou-se pouca participação, como foi o caso de oficinas oferecidas exclusivamente aos egressos na Semana Acadêmica da Faculdade em 2017, que teve pouca aderência, conforme pode ser verificado nos documentos de frequência do evento.

Os egressos foram questionados, também, sobre a importância de manter suas informações sempre atualizadas no sistema de acompanhamento de egressos e sobre consultá-lo com frequência a fim de que possam usufruir dos benefícios. Aproximadamente $70,00 \%$ dos respondentes consideraram uma tarefa relevante, o que deixa a entender o que eles fariam.

Além das questões de múltipla escolha, foram apresentadas duas questões abertas ao final do questionário. A primeira tinha por objetivo verificar quais outras ações despertariam o interesse dos egressos em participar de um Portal do Egresso e a contribuir para a avaliação e melhoria do curso. Apenas nove dos 46 respondentes fizeram contribuições, que podem ser observadas na sequência: Notícias relevantes da área de formação; Ter acompanhamento no desenvolvimento da carreira profissional após o curso, estimulando, assim, o crescimento e o aperfeiçoamento contínuo; Informações sobre vagas no portal; Troca de experiências profissionais; Agenda, notícias e outros temas relacionados à área de formação; Um fórum para troca de ideias; Comunicação direta com coordenadores dos cursos para disponibilidade de informações e auxílio; Encontros para trocas de ideias com profissionais e não necessariamente da mesma área. Também chamou a atenção o comentário de uma egressa que revela o desconhecimento do termo egresso e revela não ter desejo em acessar o portal: Eu não sou mais egressa, então não tenho acesso nem interesse em acessar o portal. 
A última questão foi disponibilizada como um espaço aberto para que os participantes pudessem apresentar outras sugestões além daquelas listadas que considerassem importantes. Essa questão obteve as sete respostas que seguem: Empréstimo de livros da biblioteca; Continuar a ter orientações para elaboração de artigos científicos e projetos para publicação por meio do Senac, processo vinculado às disciplinas de cada curso; Biblioteca; Bolsas de estudo para pós-graduação; Interação entre os participantes sobre divulgação de oportunidades de trabalhos nas respectivas áreas; Eu não sou mais egressa, então não tenho acesso nem interesse em acessar o portal, mas seria muito legal que os alunos tivessem esses serviços disponíveis com mais facilidade, pois, enquanto fui aluna, havia as palestras, mas muitos desses serviços eu nem sabia que existiam; Cursos de atualização de mercado.

Observa-se que algumas sugestões se repetem, como a opção de acesso à biblioteca e empréstimo de livros, cuja operação é de fácil execução e não implica custos adicionais à IES. Ressalta-se, ainda, que os itens relativos às questões de empregabilidade não foram destacados como de extrema relevância, o que pode ser reflexo do baixo índice de egressos que não estavam exercendo atividade remunerada no período da pesquisa. Porém, aspectos inerentes à educação continuada, como os benefícios de desconto e possibilidade de adesão a formações complementares, se mostraram como elementos de maior interesse na visão dos diplomados.

\section{CONSIDERAÇÕES FINAIS}

A Faculdade Senac Florianópolis é uma IES voltada para a formação técnica e tecnológica, com cursos superiores de curta duração, especialmente desenvolvidos para um público-alvo que pretende se especializar para atuar no setor comercial e de serviços. O perfil do egresso evidencia que há um alinhamento entre a missão da Faculdade e as características de seu alunado, uma vez que se trata de um público relativamente jovem, que, em sua maioria, já estava inserido no mercado de trabalho e buscou a formação em nível superior como uma alternativa para progredir na carreira.

A participação dos egressos na pesquisa, por curso e por ano de formatura foi equilibrada, com exceção dos recém-formados, que tiveram uma adesão menor à pesquisa. Essa constatação chamou a atenção, pois pressupõe-se que o tempo decorrido desde a formatura contribua para acentuar o distanciamento entre os egressos e a IES, o que não se concretizou neste estudo. O fato de existir um canal de relacionamento voltado ao campo profissional pode ter auxiliado na manutenção do vínculo entre os diplomados e a instituição.

A contribuição da formação para o desenvolvimento dos egressos foi percebida na avaliação positiva que fizeram do curso realizado e no desejo de dar continuidade aos estudos.

Sobre a atuação profissional, além da progressão na carreira, refletida para a maioria dos respondentes, no aumento da renda durante o avanço dos 
estudos e/ou após a formatura, 70,00\% deles trabalham na área de formação e aproximadamente a metade possui renda superior a $\mathrm{R} \$ 3.001,00$.

Com relação à criação de um Portal do Egresso com a possibilidade de oferta de serviços e benefícios aos graduados, percebeu-se que, entre os quesitos listados, os respondentes atribuíram maior importância a questões como: descontos em cursos e eventos promovidos pela Faculdade Senac ou instituições parceiras e Eventos, palestras e workshops sobre gestão. Esses aspectos contribuem com a expectativa de dar prosseguimento aos estudos e de continuar progredindo na carreira. As ações de educação continuada são uma oportunidade para a instituição criar e estreitar o vínculo com os egressos, pois configura-se como uma via de mão dupla que atende tanto às necessidades da IES como à dos graduados.

Um ponto positivo observado é que $70,00 \%$ dos respondentes destacaram como relevante se cadastrarem para manter as informações atualizadas em um Portal do Egresso, a fim de poderem usufruir dos serviços e dos benefícios sinalizados. Dessa forma, percebe-se que o estabelecimento de um Portal do Egresso será bem recebido pelos graduados da Faculdade Senac Florianópolis, já que eles demonstraram interesse em aspectos que vão além das ações relativas ao encaminhamento profissional, disponibilizadas pelo Senac/SC, especialmente porque a maioria deles já estão inseridos no mercado de trabalho.

Como sugestão de aprofundamento desta pesquisa, sugere-se que sejam realizados estudos voltados à estruturação do Portal do Egresso, como o desenvolvimento de um Banco de Dados para a coleta das informações necessárias para fomentar os processos avaliativos e decisórios da IES e a projeção dos recursos humanos e dos custos operacionais envolvidos na gestão e manutenção do sistema.

\section{REFERÊNCIAS}

\section{BRASIL. Constituição da República Federativa do Brasil, de 5 de outubro}

de 1988. Disponível em:

http://www2.camara.leg.br/legin/fed/consti/1988/constituicao-1988-5-outubro1988-322142-publicacaooriginal-1-pl.html. Acesso em: 5 jul. 2017.

BRASIL. Decreto n. 19.851, de 11 de abril de 1931. Dispõe que o ensino superior no Brasil obedecerá, de preferência, ao sistema universitário, podendo ainda ser ministrado em institutos isolados, e que a organização técnica e administrativa das universidades é instituída no presente Decreto, regendo-se os institutos isolados pelos respectivos regulamentos, observados os dispositivos do seguinte Estatuto das Universidades Brasileiras. Disponível em: http://www2.camara.leg.br/legin/fed/decret/1930-1939/decreto-19851-11-abril1931-505837-publicacaooriginal-1-pe.html. Acesso em: 5 jul. 2017.

BRASIL Lei $\mathbf{n}$. 5.540, de 28 de novembro de 1968. Fixa normas de organização e funcionamento do ensino superior e sua articulação com a 
escola média, e dá outras providências. Disponível em: http://www.planalto.gov.br/ccivil_03/leis/L5540.htm. Acesso em: 7 jul. 2017.

BRASIL. Lei n. 9.394, de 20 de dezembro de 1996. Estabelece as diretrizes e bases da educação nacional. Disponível em: http://www.planalto.gov.br/ccivil_03/leis/L9394.htm. Acesso em: 1ํ set. 2017.

BRASIL. Lei n. 10.861, de 14 de abril de 2004. Institui o Sistema Nacional de Avaliação da Educação Superior - SINAES. Disponível em: http://www.planalto.gov.br/ccivil_03/_ato2004-2006/2004/lei/110.861.htm. Acesso em: 1ํ set. 2017.

BRASIL. Parecer CNE/CES n. 436, de 2 de abril de 2001. Orientações sobre os Cursos Superiores de Tecnologia - Formação de Tecnólogo. Disponível em: http://portal.mec.gov.br/cne/arquivos/pdf/CES0436.pdf. Acesso em: 7 jul. 2017.

BRASIL. Resolução CNE/CP n. 3, de 18 de dezembro de 2002. Institui as Diretrizes Curriculares Nacionais Gerais para a organização e o funcionamento dos cursos superiores de tecnologia. Disponível em: http://portal.mec.gov.br/cne/arquivos/pdf/CP032002.pdf. Acesso em: 7 jul. 2017.

CABRAL, T. L. O.; PACHECO A. S. V. As universidades e o relacionamento com seus ex-alunos: uma análise dos portais online de egressos. In: XV COLÓQUIO INTERNACIONAL SOBRE GESTÃO UNIVERSITÁRIANA AMÉRICA DO SUL, Florianópolis, UFSC, 2015. Anais [...],Florianópolis. UFSC, 2015. Disponível em:

https://repositorio.ufsc.br/xmlui/bitstream/handle/123456789/136252/104_00267 .pdf?sequence=1\&isAllowed=y. Acesso em: 30 ago. 2017.

DIAS, S. R. Gestão de marketing. São Paulo: Saraiva, 2003.

DIAS SOBRINHO, J. Avaliação e transformações da educação superior brasileira (1995-2009): do provão ao SINAES. Avaliação: Revista da Avaliação da Educação Superior, Campinas; Sorocaba, SP, v. 15, n. 1, p. 195-224, 2010.

FÁVERO, M. L. A. A. Universidade no Brasil: das origens à Reforma Universitária de 1968. Curitiba: Editora UFPR. 2006. n. 28. p. 17-36.

GOMES, Alfredo Macedo. Exame Nacional de Cursos e política de regulação estatal do ensino superior. Programa de pós-graduação em educação da Universidade Federal de Pernambuco, Cadernos de pesquisa, $n^{\circ} 120$, novembro, 2003.

INEP - INSTITUTO NACIONAL DE ESTUDOS E PESQUISAS EDUCACIONAIS ANÍSIO TEIXEIRA. Instrumento de Avaliação de Cursos de Graduação - presencial e a distância. [2015a]. Disponível em:

http://download.inep.gov.br/educacao_superior/avaliacao_cursos_graduacao/in strumentos/2015/instrumento_cursos_graduacao_publicacao_agosto_2015.pdf. Acesso em: 27 maio 2017.

INEP - INSTITUTO NACIONAL DE ESTUDOS E PESQUISAS EDUCACIONAIS ANÍSIO TEIXEIRA. Instrumento de Avaliação Institucional

Externa. Subsidia os atos de credenciamento, recredenciamento e transformação da organização acadêmica (presencial). [2014]. Disponível em: 
http://download.inep.gov.br/educacao_superior/avaliacao_institucional/instrume ntos/2015/instrumento_institucional_072015.pdf. Acesso em: 27 maio 2017.

INEP - INSTITUTO NACIONAL DE ESTUDOS E PESQUISAS EDUCACIONAIS ANÍSIO TEIXEIRA. Relatório do Censo 2015. [2015b]. Disponível em:

http://www.abmes.org.br/arquivos/documentos/Apresentacao_Censo_Superior_ 2015.pdf. Acesso em: 11 jun. 2017.

KALSBEK, D. H. Marketing e gerenciamento de matrículas na educação superior. In: MEYER JUNIOR, Victor. MURPHY, J. Patrick (org.). Dinossauros, gazelas \& tigres: novas abordagens da administração universitária: um diálogo Brasil e Estados Unidos. 2. ed. ampliada, Florianópolis: Insular, 2003.

LOUSADA, A. C. Z.; MARTINS, G. A. Egressos como fonte de informação à gestão dos cursos de Ciências Contábeis. Revista de Contabilidade e Finanças, USP, São Paulo, n. 37, p. 73-84, 2005. Disponível em: http://goo.gl/gJwJft. Acesso em: 30 ago. 2017.

MACHADO, A. S. Acompanhamento de egressos: caso CEFET-PR unidade de Curitiba. 2001. 154p. Dissertação (Mestrado) - Universidade Federal de Santa Catarina, Centro Tecnológico. Florianópolis, 2001. Disponível em: https://repositorio.ufsc.br/xmlui/handle/123456789/81600. Acesso em: 30 ago. 2017.

MADRUGA, R. Guia de implementação de marketing de relacionamento e CRM. 1. ed. São Paulo: Atlas, 2006.

MEC - MINISTÉRIO DA EDUCAÇÃO. (Brasil). Catálogo Nacional dos Cursos Superiores de Tecnologia. [2017]. Disponível em:

http://portal.mec.gov.br/catalogo-nacional-dos-cursos-superiores-de-tecnologia. Acesso em: 30 ago. 2017.

MEIRA, M. D. D.; KURCGANT, P. Avaliação de cursos de graduação segundo os egressos. Revista da Escola de Enfermagem, São Paulo, v. 43, p. 481485, 2009.

MICHELAN, L. S. et al. Gestão de egressos em instituições de ensino superior: possibilidades e potencialidades. In: IX COLÓQUIO INTERNACIONAL SOBRE GESTÃO UNIVERSITÁRIA NA AMÉRICA DO SUL, Florianópolis, UFSC, 2009. Anais [...],Florianópolis, UFSC., 2009.

QUEIROZ, T. P. O bom filho a casa sempre torna: análise do relacionamento entre a Universidade Federal de Minas Gerais e seus egressos por meio da informação. 2014. 202p. Dissertação (Mestrado em Ciência da Informação) Universidade Federal de Minas Gerais, Belo Horizonte, 2014.

QUEIROZ, T. P.; DE PAULA, C. P. A. O relacionamento com egressos como estratégica organizacional para o desenvolvimento das instituições de educação superior. Perspectivas em Gestão \& Conhecimento, [S.I.], v. 6, n. 1, p. 4-18, 2016.

SENAC - SERVIÇO NACIONAL DE APRENDIZAGEM COMERCIAL. Página institucional [2017]. Disponível em: 
https://portal.sc.senac.br/portal/site/institucional/sobre-o-senac/sc. Acesso em: 30 ago. 2017.

TEIXEIRA, G. C. S.; MACCARI, E. A. Proposição de um plano de ações estratégicas para associações de alunos egressos baseado em benchmarking. In: XIV COLOQUIO INTERNACIONAL DE GESTÃO UNIVERSITÁRIA - CIGU, Florianópolis, Brasil, 2014. Anais [...], Florianópolis, Brasil, 2014. 